\title{
Determinants of efficient growth boundaries with balanced budgets and stochastic rents
}

\author{
Jyh-Bang Jou ${ }^{1}$ \\ Graduate Institute of National Development, National Taiwan University, Taiwan
}

\begin{abstract}
This article investigates how uncertainty in urban rents affects an efficient growth boundary designed by a regulator, who prices a congestible public good at the average cost. A landowner decides the timing of development and competes with the regulator in a dynamic Stackelberg game. The regulator anticipates this timing decision and dynamically adjusts the growth boundary accordingly. The regulator should slacken the boundary control as urban rents pass their historically high levels, which is consistent with the existing land-use planning systems. The regulator should also design a smaller urban growth boundary if uncertainty arises because uncertainty will induce the landowners to postpone development.
\end{abstract}

Keywords: balanced budgets, growth boundaries, Stackelberg game, stochastic rents

JEL Classification: G13; H23; R52; R58

${ }^{1}$ Corresponding author. Tel.: 886-2-33663331, fax: 886-2-23679684, E-mail address: jbjou@ntu.edu.tw. Address: National Taiwan University, Graduate Institute of National Development, No. 1, Sec. 4, Roosevelt Road, Taipei, 10617 Taiwan (R.O.C). 


\section{Introduction}

A city government is required to finance both infrastructure investment and the current inputs to provide public services to city residents. As the population grows, the expenditures on both of these items may increase more than proportionally if the city government wants to maintain public services at a constant level because it usually costs the government more to provide public services to suburban residents than to central city residents (Brueckner, 2011). The government may thus opt to price public services at the average cost to balance budgets and to simultaneously restrict the city boundary. Taking this concern into account, Ding, Knaap, and Hopkin (1999) have investigated the design of growth boundary controls assuming that urban rents grow at a constant rate. The purpose of this article is to demonstrate that the uncertainty in urban rents, which leads to business cycles in the real estate market, will significantly affect the design of these controls. ${ }^{1}$

This article builds a monocentric city model in which a city government provides a congestible public good such as education, fire protection, sewage, or water supply,

\footnotetext{
${ }^{1}$ Urban sprawl can have many adverse effects on local communities as a result of car-dependency on the urban fringe, congested highway systems, and less green space (Juergensmeyer and Roberts, 2003). Consequently, many local communities employ growth management controls to rectify these negative impacts. These control programs include the following strategies: time or phased growth control, as developed by Ramapo, New York; population control, listed in the Boca Raton plan in Florida; and urban growth boundary control, employed in the states of Oregon and Minnesota. Alternatively, some communities employ policies to raise the cost of development to curb growth. These policies include municipal exactions, regulatory delays in the approval process (Mayo and Sheppard, 2001), and impact fees. See the review paper by Brueckner (2007b), which investigates the effects of three commonly employed interventions, including urban growth boundaries, floor area ratio restrictions, and cost-increasing regulations.
} 
assuming that the city government prices the public good at the average cost and that the urban infrastructure is fixed. In the absence of any control, the population, and thus the city boundary, will exceed the first-best level based on pricing the public good at marginal cost. Consequently, there is scope for the regulator to design an efficient boundary control.

To examine the design of that boundary control policy, this article assumes that a landowner and the regulator compete in a dynamic Stackelberg game. ${ }^{2}$ That is, as the follower, the landowner decides the date on which to develop his/her vacant land given that he/she receives stochastic rents after development and that the regulator has already set the city boundary. As the leader, the regulator anticipates the timing for development chosen by the landowner and decides whether to reset the city boundary. Assuming that the regulator incurs sunk costs to implement the boundary control, this article shows that the regulator should expand the urban boundary if urban rents pass their historically high levels and should do nothing otherwise. This policy implication is consistent with the existing land-use planning system that requires a city government to periodically expand the urban boundary as the population grows (see Ding et al., 1999; Jaeger and Plantinga, 2007). ${ }^{3}$ This article further notes that the

\footnotetext{
2 This article thus constructs a simplified version of the hierarchical game as addressed in the literature on environmental management such as Jou (2004) and Krawczyk and Zaccour (1999).

3 This type of policy is implemented in many countries, such as the U.S., New Zealand (Cox and Pavletich, 2012), and Switzerland (Gennaio, Hersperger, and Bürgi, 2009). Furthermore, housing affordability is often cited as one of the main reasons why the regulator periodically relaxes the urban growth boundary. For example, in Portland's Washington County and in Auckland, New Zealand, the 
regulator should design a smaller growth boundary if the agricultural rents, the costs

of development, the commuting costs, and the volatility of urban rents increase.

Moreover, the regulator should design a larger growth boundary if infrastructure investment increases or urban rents are expected to grow more rapidly over time.

The remaining sections are organized as follows. The next section presents the literature review, and Section 3 lays out the basic assumptions. In Section 4, I derive a landowner's choice for development timing, the city boundary in competitive equilibrium, and the efficient growth boundary designed by the regulator. In Section 5 , I discuss the implications of the model. The final section concludes the paper and suggests directions for future research.

\section{Literature Review}

Numerous studies have focused on the issues surrounding the design of efficient growth boundaries. I will first relate my article to Brueckner (1990), Ding et al. (1999) and Jou (2012), all of which build a monocentric city model and argue that the urban growth boundary may achieve the first-best optimum. I will then relate my article to some other studies that discuss whether the urban growth boundary can be the second-best policy when a congestion externality arises.

land values are approximately 10 times higher per hectare on one side of the urban growth boundary (Cox and Pavletich, 2012) as on the other. Thus, one may conjecture that the regulator in each of these two cities is forced to relax the growth boundary control periodically to make housing more affordable inside the growth boundary. 
This article is closely related to two studies by Brueckner (1990) and Ding et al.

(1999), both of which assume that urban rents grow at a constant rate and thus remove any uncertainty. Brueckner employs the amenity-creation model, in which development exerts a negative externality on the city residents. ${ }^{4}$ Assuming that the regulator unexpectedly implements a growth boundary control that forces the landowners to postpone development, Brueckner shows that the regulator should continuously slacken the efficient growth boundary because urban rents grow continuously over time. In contrast, the model in this article allows the urban rents to move downward and shows that the regulator needs to slacken the boundary control only if the urban rents pass their historically high levels.

Similar to this article, Ding et al. (1999) consider how the regulator designs an efficient growth boundary to rectify the inefficiencies associated with the mispricing of public services. They recommend two different policies depending on whether the urban infrastructure is fixed. When the urban infrastructure is fixed, they recommend that the regulator not act before a defined date; at that defined date, the regulator should then set the city boundary once and for all. These authors further use a graph

\footnotetext{
${ }^{4}$ Several articles also employ the amenity-creation model, including Cooley and LaCivita (1982), Brueckner (1990), Engle, Navarro, and Carson (1992), Helsley and Strange (1995), Sakashita (1995), Sasaki (1998), Turnbull (2004), and Jou and Lee (2008). Cho (1997), in contrast, develops a model to demonstrate that the congestion externality caused by the boundary controls can understate the total welfare costs of regulation. Several articles, instead, employ the supply-restriction model, which argues that housing prices increase with the decrease in the housing supply that is created by growth controls. See, for example, Brueckner (1995) and Brueckner and Lai (1996). Finally, Brueckner (1997) has investigated how various financing methods for infrastructure affect the design of boundary controls. Brueckner, however, considers only the capital costs.
} 
to demonstrate that if the regulator can invest in urban infrastructure, then the regulator should release the efficient growth boundary at the point in time when the investment is made and should set it at a higher population level. This policy implication is similar to that derived in this article. However, Ding et al. do not explain which factors drive infrastructure investment in the first place. In contrast, this article argues that the uncertain demand for housing services is the main reason why the regulator periodically resets the city boundary.

A recent paper by Jou (2012), which investigates the issue regarding the design of efficient growth boundaries assuming that urban rents are stochastic over time, also suggests that the regulator should slacken the efficient growth boundary once urban rents past their historical high levels. However, that paper assumes population externalities in a circular city (Brueckner, 1990) rather than mispricing of a public good in a linear city as the main reason of market failures. That paper assumes that each landowner, who receives nothing from the vacant land, must decide the timing and intensity of land development. As such, that paper is not able to investigate how infrastructure investment and the agricultural rents affect the design of efficient growth boundaries. Furthermore, that paper finds that uncertainty in urban rents exhibits an indeterminate effect (rather than a negative effect) on efficient growth boundaries. 
This article is related to previous work that investigates whether a growth boundary control is a good substitute for congestion tolls when a congestion externality exists. All of Arnott (1979), Kanemoto (1977), and Pines and Sadka (1985) show that a growth boundary control in a monocentric congested city can reduce the deadweight loss arising from the congestion externality. Both Brueckner (2007) and Kono, Joshi, Kato, and Yokoi (2012), however, argue that the welfare gain may be very small, and they employ plausible parameter values to quantify it. Furthermore, Anas and Pines (2008), and Anas and Rhee (2006; 2007) show that in a system of congested cities in which people make discretionary trips in all directions, a congestion toll that rectifies the congestion externality will push the city residents to reside and work in the suburbs. Consequently, a boundary with any stringency is harmful and is not a second-best policy compared to a congestion toll. In contrast, this article builds a monocentric city model and assumes that the commuting costs are exogenously given, thus avoiding the congestion externality.

\section{The Model}

The basic model extends the models of Capozza and Helsley (1990) and Ding et al. (1999). Consider a linear open city of unit width with perfectly competitive factor and product markets. The city has all employment (the CBD) located at one end. Let us begin from date $t=0$ at which the city has just formed, and thus the city boundary is 
zero. An absentee landowner, who is also a developer, has one unit parcel of land at location $D$ that yields a rent equal to $\gamma(\geq 0)$ and contemplates whether to develop that parcel of land after date $t \geq 0$. It costs the landowner $F$ to develop his/her vacant land, which is fully irreversible. Without loss of generality, I assume that the landowner is risk-neutral and faces a discount rate denoted by $\rho$.

As in Ding et al. (1999), I assume that there exists a congestible public good, $z$, which must be provided to all residents of the urban area but is rival in consumption. Examples of these types of goods include education, water and waste-water services, and police and fire protection. The public good is produced with a fixed stock of urban infrastructure, $k$, and the variable input, $m$, such that the public good production function can be specified as ${ }^{5}$

$$
z=G(k, m, n),
$$

where $n$ represents the urban population and $\partial G / \partial k>0, \partial G / \partial m>0$, and $\partial G / \partial n<0$, implying that the level of the public good increases with the infrastructure and the variable input and decreases with population.

Assuming that a local government adjusts the variable input to maintain $z$ fixed at a constant level, $\bar{z}$, I can thus use Equation (1) and transform the variable input $m$ in terms of $n$ and $k$. Assuming further that the price of the variable input is

\footnotetext{
${ }^{5}$ Similar to Ding et al. (1999), I assume that $k$ is established before time 0 . 
unit, I can thus specify a variable cost function as $m=C(n, k)$, where $\partial C / \partial n=-(\partial G / \partial n) /(\partial G / \partial m)>0 \quad, \quad$ and $\quad \partial C / \partial k=-(\partial G / \partial k) /(\partial G / \partial m)<0 \quad$.

Without loss of generality, I specify the variable cost function as

$$
m=C(n, k)=n^{2} g(k), \quad g^{\prime}(k)<0 .
$$

Equation (2) indicates that the cost of maintaining a constant level of the public good grows with the population at an increasing rate, thus ensuring that the regulator can implement the boundary control to enhance the social welfare. ${ }^{6}$ The equation also shows that the marginal cost of supplying the public good is decreasing with the level of infrastructure. Equation (2) resembles that used in Brueckner (1997) and in the literature on clubs. However, Brueckner (1997) considers the financing of incremental infrastructure, while I do not. Instead, I focus only on the financing of the variable input and assume that landowners, rather than renters, must pay the cost of providing the public good.

Following Ding et al. (1999), I assume that the local government sets the price of the public good at the average cost rather than the marginal cost to yield a balanced budget. Consequently, city residents may become better off when the population is reduced through the application of a growth boundary control. The control has no effect on the utility level of consumers, however, because the city is too small. I also

\footnotetext{
${ }^{6}$ The main conclusion of this article still holds if I specify a more generalized function such as $m=n^{\lambda} g(k)$, where $\lambda>1$. However, unless $\lambda=2$, I am unable to derive an analytically tractable solution for the optimal growth boundary.
} 
assume that all consumers have identical utility functions, denoted by $v(c, \ell, z)$, where $c$ is a numeraire good, $\ell$ is urban land, and $z$ is the public good. Urban residents at location $D$ earn income $y(t)$ and must pay for the numeraire good $c$, land rents, $R$, and transportation costs $\theta D$, where $D$ is the distance (in miles) to the $\mathrm{CBD}$ and $\theta(>0)$ is the commuting cost per mile. To simplify the analysis, I assume that each resident consumes one unit of developed land, and thus the budget constraint becomes $y(t)=c+R+\theta D$. Noting that the public good is supplied at a fixed level $\bar{z}$, I can construct a representative utility function as given by

$$
v(c, l, z)=v(c, 1, \bar{z})=u(t) .
$$

Equation (3) shows that, under open city assumptions, the resident utility must equal the exogenous utility level, $u(t)$. Without loss of generality, I explicitly impose the utility function to be quasi-linear as given by $v(c, 1, \bar{z})=c+\bar{z}$. Replacing $c$ by $v(c, 1, \bar{z})-\bar{z}$, using both Equation (3) and the budget constraint, and defining $x(t)$ as $y(t)+\bar{z}-u(t)$, i.e., the sum of income and the fixed stock of urban infrastructure net of the exogenous utility level, the bid rent function per unit of urban land is thus given by

$$
R(D, x(t))=x(t)-\theta D
$$

I assume that the factor $x(t)$ evolves stochastically over time and follows the arithmetic Brownian motion 


$$
d x(t)=\alpha d t+\sigma d \Omega(t), \alpha>0, \quad \sigma>0,
$$

where $\alpha$ is the constant drift rate, $\sigma$ is the instantaneous volatility of $x(t)$, and $d \Omega(t)$ is an increment to a standard Wiener process. ${ }^{7}$

Given that the public good is inefficiently priced, the local government can thus implement two broad types of policies to correct it (Turnbull, 2004): (i) fees, or special exactions, imposed on the newly developed property; or (ii) direct quantity restrictions in the form of urban growth boundaries, greenbelt preserves, land banks, or development moratoria. I will focus only on the design of an efficient growth boundary control.

To examine the design of this policy, I assume that a landowner at location $D_{0}$ and the regulator compete in a dynamic Stackelberg game. That is, as the follower, the landowner chooses a date as of which to develop his/her vacant land. As the leader, the regulator anticipates this timing decision and sets an efficient growth boundary accordingly. I further assume that the landowner at location $D_{1} \quad\left(>D_{0}\right)$, who has not developed his/her vacant land, anticipates that the regulator will adjust the urban growth boundary in the future. The game played by the regulator and the landowner at location $D_{1}$ then resembles that between the regulator and the landowner at location

\footnotetext{
${ }^{7}$ My specification is the same as that assumed in Capozza and Helsley (1990), Capozza and Li (1994), and Capozza and Sick (1994). Furthermore, one can derive the evolution of $x(t)$ as specified in Equation (5) by assuming that both $y(t)$ and $u(t)$ follow a joint arithmetic Brownian motion (see, e.g., Dixit and Pindyck, 1994; Jou, 2012).
} 
$D_{0}$. This type of sequential game will arise repeatedly until the landowner at the outer boundary of the planner's jurisdiction has developed his/her vacant land. I will sequentially investigate the decision of the landowner at location $D$ and the regulator in the following section.

\section{Choices of Development Timing and Efficient Boundary Controls}

I assume that the regulator implements a growth boundary control at the initial date time $t=0$ before any landowner makes his/her development decision. Thus, a landowner at location $D$ will take this policy as given when he/she looks to develop. The regulator, however, can slacken the control if needed at any future date. Let us denote $x(0)$ as $x$ and $T$ as the time of development here and subsequently. The landowner at location $D$ must determine the date at which it is optimal to develop his/her parcel of land to maximize the expected net present value of that parcel of land, which is given by

$$
E_{0}\left[\int_{0}^{T} e^{-\rho \tau} \gamma d \tau+\int_{T}^{\infty} e^{-\rho \tau}(x(\tau)-\theta D-n g(k)) d \tau-e^{-\rho T} F\right]
$$

Equation (6) indicates that the expected net present value of returns to one unit of vacant land at location $D$ is the sum of the returns to that parcel of land until time $T$, plus the expected present value of the land rent beginning at the time of development, less the expected present value of the sum of the cost incurred for using the public good and the up-front development costs. Note that the landowner treats the 
cost of public goods, $n g(k)$, as exogenously given, even though in equilibrium, the population, $n$, will be equal to the growth boundary set by the regulator.

Equation (6) can be rewritten as follows:

$$
\frac{\gamma}{\rho}+E_{0}\left[\int_{T}^{\infty} e^{-\rho \tau}(x(\tau)-\theta D-n g(k)-\gamma) d \tau-e^{-\rho T} F\right]
$$

In Equation (7), the first term is the expected present value of the agricultural rents, assuming that the vacant land is never converted to urban use, while the remaining term is the value of the landowner's option to delay development. The problem for the landowner is then equivalent to choosing the date on which to maximize this option value and, therefore, can be written as follows:

$$
V(x)=\max _{T} E_{0}\left[\int_{T}^{\infty} e^{-\rho \tau}[x(\tau)-\theta D-n g(k)-\gamma] d \tau-e^{-\rho T} F\right] .
$$

The solution for $V(x)$ must satisfy the fundamental differential equation of optimal stopping given by (see, e.g., Dixit and Pindyck, 1994; Harrison, 1985)

$$
\frac{1}{2} \sigma^{2} \frac{\partial^{2} V(x)}{\partial x^{2}}+\alpha \frac{\partial V(x)}{\partial x}-\rho V(x)=0 .
$$

The ordinary differential equation given by Equation (9) has a solution with the functional form $e^{\beta x}$. Substituting this functional form into Equation (9) yields the quadratic equation given by

$$
\phi(\beta)=-\frac{1}{2} \sigma^{2} \beta^{2}-\beta \alpha+\rho=0
$$

The solution to Equation (9) is thus given by

$$
V(x)=A_{1} e^{\beta_{1} x}+A_{2} e^{\beta_{2} x},
$$


where $A_{1}$ and $A_{2}$ are constants to be determined, and $\beta_{1}$ and $\beta_{2}$ are, respectively, the larger and smaller roots of Equation (10):

$\beta_{1}=-\frac{\alpha}{\sigma^{2}}+\frac{1}{\sigma^{2}} \sqrt{\alpha^{2}+2 \rho \sigma^{2}}>0$, and $\beta_{2}=-\frac{\alpha}{\sigma^{2}}-\frac{1}{\sigma^{2}} \sqrt{\alpha^{2}+2 \rho \sigma^{2}}<0$.

The landowner at location $D$ chooses the timing of the development, which is characterized by $x^{*}$, the critical value of $x$ that triggers land development. This critical value and $A_{1}$ and $A_{2}$ in Equation (11) are obtained from the boundary conditions given by

$$
\begin{aligned}
& \lim _{x \rightarrow-\infty} V(x)=0, \\
& \frac{\gamma}{\rho}+V\left(x^{*}\right)=\frac{x^{*}}{\rho}+\frac{\alpha}{\rho^{2}}-\frac{\theta D}{\rho}-\frac{n g(k)}{\rho}-F,
\end{aligned}
$$

and

$$
\frac{\partial V\left(x^{*}\right)}{\partial x}=\frac{1}{\rho}
$$

Equation (13) is the limit condition, which states that the value of the landowner's option to develop one unit parcel of land is worthless when the demand for housing services is extremely poor, i.e., when the stochastic factor $x$ approaches minus infinity. Equation (14) is the value-matching condition, which states that at the chosen date of development, the landowner at location $D$ should be indifferent as to whether the parcel of land is developed or not. Equation (15) is the smooth-pasting condition, which requires that the landowner not obtain any arbitrage profits if 
deviating from the chosen date of development.

Solving Equations (13) to (15) simultaneously yields

$$
\begin{aligned}
& A_{1}=\frac{1}{\rho \beta_{1}} e^{-\beta_{1} x^{*}}, \\
& A_{2}=0,
\end{aligned}
$$

and

$$
x^{*}(D, n)=\gamma+\rho F+n g(k)+\theta D+\frac{1}{\beta_{1}}-\frac{\alpha}{\rho} .
$$

Substituting $A_{1}$ given by Equation (16) and $A_{2}$ given by Equation (17) into Equation (11) yields the value of the landowner's option to postpone development as given by

$$
V(x)=\frac{1}{\rho \beta_{1}} e^{\beta_{1}\left(x-x^{*}(D, n)\right)} .
$$

The value of undeveloped land and that of urban land can be derived by substituting

$x$ for $x^{*}$ on the left-hand and right-hand side (except for the last term), respectively, of Equation (14) and are thus given by

$$
V_{a}(x, D, n)=\frac{\gamma}{\rho}+\frac{1}{\rho \beta_{1}} e^{\beta_{1}\left(x-x^{*}(D, n)\right)} \text {, if } x<x^{*}(D, n),
$$

and

$$
V_{u}(x, D, n)=\frac{x}{\rho}+\frac{\alpha}{\rho^{2}}-\frac{\theta D}{\rho}-\frac{n g(k)}{\rho}, \text { if } x \geq x^{*}(D, n) .
$$

Differentiating $x^{*}(D, n)$ in Equation (18) with respect to its underlying parameters yields the following results.

Proposition 1. Compared to a landowner in another city, a landowner in one city will 
postpone development $\left(x^{*}(D, n)\right.$ increases $)$ if the following are true: $(i)$ the landowner receives higher agricultural rents ( $\gamma$ increases); (ii) the landowner expects urban rents to be more volatile ( $\sigma$ increases); (iii) the landowner expects urban rents to grow less rapidly over time ( $\alpha$ decreases); (iv) the landowner incurs larger development costs ( $F$ increases); $(v)$ the landowner's renter is provided with less infrastructure stock ( $k$ decreases); ( $v i)$ the landowner's renter incurs greater commuting costs ( $\theta$ increases); and (vii) the landowner's land is distant from the CBD ( $D$ increases).

\section{Proof: See Appendix A.}

The reason for Proposition 1 is as follows. When deciding whether to develop one unit parcel of land, a landowner in a certain city must compare the value of undeveloped land shown by Equation (20) (including the expected present value of the agricultural rents and the option value from delaying development), with the value from development shown by Equation (21) net of the development cost, $F$. The landowner in this city will postpone development either because he/she has a higher value of undeveloped land (scenarios (i) and (ii)), because he/she has a lower net value from development (scenarios (iv)-(vii)), or because he/she has a higher value of undeveloped land net of the net value from development (scenario (iii)), compared to a landowner in another city. 
Having determined the development strategy $\left(x^{*}\right)$ adopted by the landowner at a given location $D$, I now follow Fujita (1982) and Turnbull (1988) and ask the following question: Given a state of nature denoted by $x(t)$, what location $D_{d}^{*}(x(t))$ will be associated with the state-contingent chosen date of development? The landowner understands the urban growth process and acts with rational expectations. In particular, he/she knows that the city grows outward over time and thus realizes that his/her land will lie at the city's boundary at the time of conversion. Because the city is linear and of unit width, the population $n$ is thus equal to the distance to the boundary, given that each resident consumes one unit of urban land. In other words, in equilibrium, when the land at location $D$ is converted, the population $n$ will be equal to $D$. Following Capozza and Helsley (1990), I can impose $n=D$, replace $x^{*}$ with $x(t)$ and $D$ with $D_{d}^{*}(x(t))$ and then transform Equation (18) into the following:

$$
D_{d}^{*}(x(t))=\frac{\left(x(t)-a_{0}\right)}{(\theta+g(k))},
$$

where $a_{0}=\rho F+\gamma+\frac{1}{\beta_{1}}-\frac{\alpha}{\rho}$, which is required to be smaller than $x(t)$.

Equation (22) can be interpreted as follows. At the initial date $t=0$ when the rent-shift factor is given by $x(0)$, some landowners closer to the CBD will develop and thus push the city boundary to $D_{d}^{*}(x(0))$ in Equation (22). Suppose that at some date $t$ the rent-shift factor $x(t)$ exceeds $x(0)$ for the first time. Some landowners 
will then develop their vacant lands further away from the $\mathrm{CBD}$, increasing the city boundary until $x^{*}$ increases to $x(t)$. Equivalently, if the distance from the CBD, $D_{d}^{*}(x(0))$, is less than the $D_{d}^{*}(x(t))$ given by Equation (22), then some landowners will develop their vacant lands further away from the CBD until the city boundary is increased to the point $D_{d}^{*}(x(t)) .{ }^{8}$ Because the city grows outward, $D_{d}^{*}(x(t))$ is, in fact, the equilibrium city boundary at time $t$.

Differentiating $D_{d}^{*}(x(t))$ with respect to its underlying parameters yields the following results.

Proposition 2. In the absence of any control, compared to another city, the boundary of a city will contract $\left(D_{d}^{*}(x(t))\right.$ decreases) if the following are true: $(i)$ a landowner in the city receives higher agricultural rents ( $\gamma$ increases); (ii) the landowner in the city expects urban rents to be more volatile ( $\sigma$ increases); (iii) the landowner in the city expects urban rents to grow less rapidly over time ( $\alpha$ decreases); (iv) the landowner in the city incurs larger development costs ( $F$ increases); $(v)$ the regulator in the city decreases the stock of infrastructure ( $k$ decreases); and (vi) the residents in the city incur greater commuting costs ( $\theta$ increases).

\section{Proof: See Appendix B.}

The results of Proposition 2 follow directly from Proposition 1. Specifically, if an

\footnotetext{
8 The above argument resembles that of Pindyck (1988) when he explains the timing decision for a firm undertaking a continuous investment project. See also Lee and Jou (2010) for a thorough discussion of this issue.
} 
exogenous factor leads a landowner in one city to be more hesitant in land development than a landowner in another city, then it will also cause the former city to have a smaller boundary. For example, suppose that a landowner in one city expects urban rents to be more volatile than in another city. As indicated by Proposition 1(ii), the landowner in the city will develop at a later date, because his/her option value from waiting becomes more valuable. As a result, the equilibrium city boundary will be smaller because the landowner is less inclined to transform his/her vacant land to urban use, compared to a landowner in another city.

One can compare $D_{d}^{*}(x(t))$ in Equation (22) with that derived from the first-best case in which the regulator prices the public good at marginal cost, $2 n g(k)$. Following similar procedures to those from Equations (6) to (22), and replacing $n g(k)$ by $2 n g(k)$ in these equations yields the first-best growth boundary as given by

$$
D_{f}^{*}(x(t))=\frac{\left(x(t)-a_{0}\right)}{(\theta+2 g(k))}
$$

Given that the marginal cost of supplying the public good, $2 n g(k)$, is higher than the average cost of supplying the public good, $n g(k)$, the equilibrium growth boundary shown in Equation (22) is thus broader than the first-best growth boundary shown in Equation (23). Consequently, it is possible for the regulator to implement a growth boundary control that enhances the social welfare as analyzed below. 
Because consumer utility is exogenous in the model, the planner's goal is to choose an efficient boundary control to maximize the total land value, net of the cost to implement the policy. To derive the total land value, the value expression in Equation (6) is integrated across all locations D in the planner's jurisdiction. Denote the city boundary set by the social planner as $D_{c}(\tau)$; then, the population, $n(\tau)$, will be equal to $D_{c}(\tau)$ given that the city is linear and has one unit width. Imposing this constraint yields the objective function of the planner as given by the following:

$$
\begin{aligned}
& W\left(x, D_{c}\right)=\underset{\{D c(\tau)\}}{\operatorname{Max}} E_{0}\left[\int_{0}^{D_{c}(\tau)} V_{u}\left(x(\tau), D, D_{c}(\tau)\right) d D+\int_{D_{c}(\tau)}^{B} V_{a}\left(x(\tau), D, D_{c}(\tau)\right) d D(24)\right. \\
& \left.-\int_{0}^{D_{c}(\tau)} F d D-e^{-\rho \tau} q d D_{c}(\tau)\right], \quad d D_{c}(\tau) \geq 0,
\end{aligned}
$$

where the outer boundary of the planner's jurisdiction, denoted by $B$, is assumed to be sufficiently large such that $B>D_{c}(\tau)$. In Equation (24), the term $d D_{c}(\tau)$ indicates that the regulator implements a marginal boundary control policy: it will be greater than zero when the regulator slackens the control at time $\tau$ and will be equal to zero otherwise. This indicates that the regulator can slacken the urban boundary an infinitesimal amount, which not only helps me to derive an analytically tractable solution for $D_{c}(\tau)$ but is also a reasonable approximation for the real world phenomenon in which the regulator changes the urban boundary in a lumpy amount. Inside the brackets of Equation (24), the first integral is the total urban land value, the second integral is the total agricultural land value, the third integral is the total 
development costs, and the final term is the expected present value of the administration costs to slacken the boundary control, with $q$ representing the administration cost per unit width of land. Conceivably, the administration costs include the costs for collecting data, forecasting the demand for land development, and analyzing the alternative plans through a cost-benefit evaluation.

Equation (24) indicates that the game played by the regulator and landowners is a Stackelberg type game because the regulator anticipates the development decision of a landowner who has a parcel of land at any location $D$ and thus understands the value of that parcel of land both after development $V_{u}(\cdot)$ and before development, $V_{a}(\cdot)$. Taking the decisions of all of the landowners into account, the regulator can then dynamically adjust the growth boundary over time to achieve the social optimum.

The regulator faces an instantaneous control problem as addressed by Bertola and Caballero (1994), who also suggest that we can decompose $W\left(x, D_{c}\right)$ into a non-option term $W_{n}\left(x, D_{c}\right)$ and another option term $W_{0}\left(x, D_{c}\right)$. The non-option term is derived at the instant at which the control is imposed. Thus, the marginal value of slackening the control immediately is equal to

$$
\begin{aligned}
\frac{\partial W_{n}\left(x, D_{c}\right)}{\partial D_{c}} & =V_{u}\left(x, D_{c}, D_{c}\right)-F-V_{a}\left(x, D_{c}, D_{c}\right)-\frac{g(k)}{\rho} D_{c} \\
& -\frac{g(k)}{\rho} \int_{D_{c}}^{B} e^{\beta_{1}\left(x-x^{*}\left(D, D_{c}\right)\right)} d D-q .
\end{aligned}
$$


On the right-side of Equation (25), the first three terms represent the net gain from transforming agricultural land to urban use at location $D_{c}$. The fourth term shows the extra burden borne by the existing owners of developed land because more people move into urban areas to share the congestible public good. The fifth term shows the loss of the option value borne by the existing owners of undeveloped land because they will postpone development as the regulator slackens the boundary control (because $\left.\partial x^{*}\left(D, D_{c}\right) / \partial D_{c}>0\right)$. Finally, the last term is the administration cost.

However, the regulator's option value from delaying the marginal control must obey the differential equation given by

$$
\frac{1}{2} \sigma^{2} \frac{\partial^{2}\left(\partial W_{0}\left(x, D_{c}\right) / \partial D_{c}\right)}{\partial x^{2}}+\alpha \frac{\partial\left(\partial W_{0}\left(x, D_{c}\right) / \partial D_{c}\right)}{\partial x}-\rho \frac{\partial W_{0}\left(x, D_{c}\right)}{\partial D_{c}}=0 .
$$

As a result,

$$
\frac{\partial W_{0}\left(x, D_{c}\right)}{\partial D_{c}}=d_{1} e^{\beta_{1} x}+d_{2} e^{\beta_{2} x},
$$

where $d_{1}$ and $d_{2}$ are constants to be determined, and both $\beta_{1}$ and $\beta_{2}$ are defined in Equation (12).

The critical level of $x$ that triggers the regulator to implement the marginal control, denoted by $x^{* *}$, and $d_{1}$ and $d_{2}$ in Equation (27), is determined by the following boundary conditions:

$$
\lim _{x \rightarrow-\infty} \frac{\partial W_{0}\left(x, D_{c}\right)}{\partial D_{c}}=0
$$




$$
\frac{\partial W_{0}\left(x^{* *}, D_{c}\right)}{\partial D_{c}}=\frac{\partial W_{n}\left(x^{* *}, D_{c}\right)}{\partial D_{c}},
$$

and

$$
\frac{\partial^{2} W_{0}\left(x^{* *}, D_{c}\right)}{\partial D_{c} \partial x}=\frac{\partial^{2} W_{n}\left(x^{* *}, D_{c}\right)}{\partial D_{c} \partial x}
$$

Equation (28) is the limit condition, which states that the option value of the regulator delaying the marginal control becomes worthless when the demand for housing services is extremely poor. Equation (29) is the smooth-pasting condition, while Equation (30) is the super-contact condition, which requires that the regulator does not obtain any arbitrage profits if deviating from the rule determined by the smooth-pasting condition.

Solving Equations (28) to (30) simultaneously yields

$$
x^{* *}=\gamma+\rho F+(\theta+2 g(k)) D_{c}+\frac{1}{\beta_{1}}-\frac{\alpha}{\rho}+q .
$$

Following Capozza and Helsley (1990), I can write the efficient growth boundary as a function of the state of nature as $D_{c}^{*}(x(t))$. Substituting $D_{c}$ by $D_{c}^{*}(x(t))$ and $x^{* * *}$ by $x$ in Equation (31) and rearranging yields

$$
D_{c}^{*}(x(t))=\frac{\left(x(t)-a_{0}-q\right)}{(\theta+2 g(k))},
$$

where $a_{0}=\rho F+\gamma+\frac{1}{\beta_{1}}-\frac{\alpha}{\rho}$.

Equation (32) indicates that if the administration cost, $q$, is equal to zero, then the efficient growth boundary will be the same as the first-best level, $D_{f}^{*}(x(t))$, 
shown in Equation (23). When the administration cost is not negligible, however, the efficient growth boundary will be lower than the first-best level.

\section{Model Implications}

Differentiating $D_{c}^{*}(x(t))$ with its underlying parameters yields the main conclusions of this article, as stated below.

Proposition 3: (i) The optimal size of the urban growth boundary increases with the stochastic rent-shift factor, $x(t)$. (ii) The optimal size of the urban growth boundary falls with the agricultural rents, $\gamma$, the development costs, $F$, the commuting costs, $\theta$, the administration costs, $q$, and the instantaneous volatility of the stochastic rent-shift factor $x(t), \sigma$. (iii) The optimal size of the urban growth boundary increases with the infrastructure, $k$, and the drift rate of the stochastic rent-shift factor $x(t), \alpha$.

\section{Proof: See Appendix C.}

Proposition 3(i), which relates the evolution of $x(t)$ to the efficient growth boundary, requires further elaboration as follows. At the initial date 0 when the city's boundary is zero, the regulator announces that those who own lands within the distance $D_{c}^{*}(x(0))$ from the CBD can develop their lands. The regulator then incurs a sunk administration cost equal to $q D_{c}^{*}(x(0))$. Thereafter, the regulator will slacken 
the boundary control whenever $x(t)$ passes its historically high level but will do nothing otherwise. ${ }^{9}$ More precisely, suppose that $x(\tau)$ passes $x(0)$ for the first time at some future date $\tau$. The regulator will then slacken the growth boundary by a level equal to $D_{c}^{*}(x(\tau))-D_{c}^{*}(x(0))$ and will thus incur a cost equal to $q\left[D_{c}^{*}(x(\tau))-D_{c}^{*}(x(0))\right]$. The regulator will slacken the growth boundary again at some future date $\tau^{\prime}>\tau$ provided that $x\left(\tau^{\prime}\right)$ passes $x(\tau)$ for the first time. This article thus yields a policy implication that is consistent with the existing land-use planning system that requires a city government to periodically expand the urban boundary as the population grows (Ding et al., 1999; Jaeger and Plantinga, 2007). Such a policy also arises in Jou (2012), which, however, assumes that market failures come from population externalities rather than mispricing of a public good as addressed in this article.

My stochastic model $(\sigma>0)$ can accommodate the non-stochastic model $(\sigma=0)$ specified by Ding et al. (1999) as a polar case. Suppose that $\alpha>0$. Substituting $\sigma=0$ into Equation (10) yields $\beta_{1}=\rho / \alpha$, and thus in the absence of any uncertainty, the critical level of $x(t)$ that triggers land development, as shown in Equation (18), and the equilibrium city boundary, as shown in Equation (22), will become, respectively,

\footnotetext{
${ }^{9}$ This policy implies that if the population declines such that the demand for housing services declines and thus the land price declines, then the regulator should do nothing.
} 


$$
x^{*}(D, n)=\gamma+\rho F+n g(k)+\theta D,
$$

and

$$
D_{d}^{*}(x(t))=\frac{(x(t)-\gamma-\rho F)}{(\theta+g(k))} .
$$

I provide a rigorous proof for $x^{*}(D, n)$ shown in Equation (33) in Appendix $D$.

Figure 1 illustrates the main difference between my result and that derived by Ding et al. (1999), assuming that urban rents grow at a constant rate, $\alpha$. In the graph, the horizontal axis, $x(t)$, has a one-to-one correspondence with calendar time $t$ because $x(t)=x(0)+\alpha t$. The path $D_{d}^{*}$ is as defined in Equation (34), and $D_{c}^{*}$ is the same as defined in Equation (32) except for the substitution of $\sigma=0$. Ding et al. assume that the regulator implements an efficient growth boundary control once and for all. In other words, the regulator imposes no control before a critical date, $t^{*}$, and then sets the city boundary at a fixed level, $D_{d}^{*}\left(x\left(t^{*}\right)\right)$, afterwards. Without any uncertainty, Ding et al. and I present two alternative methods for controlling the city boundary. My method is similar to that proposed by Brueckner (1990), which is more lenient toward those landowners whose lands are distant from the CBD. In addition, the control also accommodates the situation in which the demand for housing services increases over time such that urban rents also increase over time.

When there is uncertainty in the demand for housing services, it is not plausible for a regulator to directly control the development timing and so it is infeasible for the 
regulator to implement the control set in Ding et al. (1999). It is, however, still possible for the regulator to implement the marginal boundary control as addressed in my framework.

In Ding et al.'s framework, the efficient growth boundary is the same as $D_{d}^{*}(x(t))$ shown in Equation (22) for some particular time $t=t^{*}$. Consequently, these authors conclude that the optimal size of the growth boundary will be smaller if either the development cost, the agricultural rent, or the commuting cost increases or if the stock of infrastructure decreases. These scenarios are consistent with the four scenarios stated in Proposition 3. In Proposition 3, I further conclude that the optimal size of the urban growth boundary will be smaller if (i) the landowners expect urban rents to grow less rapidly over time; (ii) the regulator incurs greater costs to implement the control policy; and (iii) the landowners expect urban rents to be more volatile. The last implication, which arises because landowners will respond to postpone development as shown in Proposition 1(ii), is especially important because it is unique to my model; Ding et al. (1999) do not consider uncertainty.

Given that the equilibrium city boundary is increasing with the stock of infrastructure, as shown by Proposition 3(iii), Ding et al. (1999) thus argue that their policy implication will change if the regulator is able to invest in infrastructure. However, they are unable to derive determinate comparative-statics results when 
allowing the regulator to simultaneously choose the investment in infrastructure and the size of the urban growth boundary. They thus use a graph to demonstrate that the regulator should release the urban growth boundary at the point when the investment in infrastructure is made and should set it at a higher population level. This policy implication resembles that derived in this article. However, Ding et al. do not explain the forces that influence the investment in infrastructure in the first place, while I argue that the uncertain demand for housing services is the main reason why the regulator periodically expands the urban boundary.

\section{Conclusion}

This article investigates how uncertainty in urban rents affects an efficient growth boundary designed by a regulator, who prices a congestible public good at average cost. I assume that a landowner decides the timing of development and competes with the regulator in a dynamic Stackelberg game. The regulator anticipates this timing decision and dynamically adjusts the growth boundary accordingly. The regulator should expand the urban growth boundary as the urban rents pass their historically high levels, which is consistent with the existing land-use planning systems. The regulator should also design a smaller urban growth boundary if uncertainty arises because the landowners will respond to delay development.

This article builds a simplified model and thus entails some limitations. First, this 
article considers an open rather than a closed city. As Brueckner (1990) indicates, an open city model implies that population pressure and the resulting excess demand for housing services plays no role in determining the market impact of the growth controls. One can follow the supply-restriction model, as outlined in both Brueckner (1995) and Helsley and Strange (1995), to take this concern into account. Second, this article assumes that landlords live outside of the city, and thus does not consider owner-occupied homes. One may follow Brueckner and Lai (1996) to take owner-occupants into account. Third, this article assumes that the commuting cost per mile is independent of location, thus ignoring externalities arising from traffic congestion, which some researchers believe to be one of the main reasons that regulators should implement urban boundary controls. One may consider traffic congestion by following Anas and Rhee (2006;2007), Brueckner (2007a), Kono et al. (2012), and Wheaton (1998). Finally, this article assumes that infrastructure investment is fixed even though the city grows. One may follow Brueckner (1997) to consider the incremental financing problem of infrastructure investment. I leave all of these extensions to future research.

\section{Acknowledgements}

I would like to thank the editor (Bernard Fingleton), two anonymous reviewers, and seminar participants at the $15^{\text {th }}$ AsRES Conference held in Kaohsiung in July 
2010. Financial support under Grant NSC-98-2410-H-002-096 from the National

Science Council, Executive Yuan, R.O.C., is gratefully acknowledged

\section{Appendix A: Proof of Proposition 1}

All scenarios except for changes in $\sigma$ and $\alpha$ are obvious. Differentiating $x^{*}(D, n)$ with respect to $\sigma$ yields

$$
\frac{d x^{*}(D, n)}{d \sigma}=\frac{-1}{\beta_{1}^{2}} \frac{d \beta_{1}}{d \sigma}>0,
$$

where

$$
\frac{d \beta_{1}}{d \sigma}=\frac{\partial \phi\left(\beta_{1}\right) / \partial \sigma}{-\partial \phi\left(\beta_{1}\right) / \partial \beta_{1}}=\frac{-\sigma \beta_{1}^{2}}{\sigma^{2} \beta_{1}+\alpha}<0
$$

and $\phi(\beta)$ is defined in Equation (10). Equation (10) also suggests that $\beta_{1} \beta_{2}=\frac{-2 \rho}{\sigma^{2}}$ and $\beta_{1}+\beta_{2}=\frac{-2 \alpha}{\sigma^{2}}$. Consequently, $\frac{1}{\beta_{1}}-\frac{\alpha}{\rho}=-\frac{1}{\beta_{2}}$. Differentiating $x^{*}(D, n)$ with respect to $\sigma$ thus yields

$$
\frac{d x^{*}(D, n)}{d \alpha}=\frac{1}{\beta_{2}^{2}} \frac{d \beta_{2}}{d \alpha}<0,
$$

where

$$
\frac{d \beta_{2}}{d \alpha}=\frac{\partial \phi\left(\beta_{2}\right) / \partial \alpha}{-\partial \phi\left(\beta_{2}\right) / \partial \beta_{2}}=\frac{-\beta_{2}}{\sigma^{2} \beta_{2}+\alpha}<0
$$

\section{Q.E.D.}




\section{Appendix B: Proof of Proposition 2}

All scenarios except for changes in $\sigma$ and $\alpha$ are obvious. Note that $x^{*}(D, n)$ and $a_{0}$ in Equation (22) has the relationship $x^{*}(D, n)=a_{0}+n g(k)+\theta D$. Given that $D_{d}^{*}(x(t))$ is negatively related to $a_{0}$, it thus follows that the sign of $d D_{d}^{*}(x(t)) / d \sigma$ is opposite to the sign of $d x^{*}(D, n) / d \sigma$, and the sign of $d D_{d}^{*}(x(t)) / d \alpha$ is opposite to the sign of $d x^{*}(D, n) / d \alpha$.

\section{Q.E.D.}

\section{Appendix C: Proof of Proposition 3}

There is a slight difference between $D_{d}^{*}(x(t))$ shown by Equation (22) and $D_{c}^{*}(x(t))$ shown by Equation (32). On the right-hand side of Equation (22), if I deduct $q$ from the numerator and replace $g(k)$ with $2 g(k)$ in the denominator, then I derive the value of $D_{c}^{*}(x(t))$. Thus, I conclude that the comparative-statics results for $D_{d}^{*}(x(t))$ stated in Proposition 2 are qualitatively the same as those for the efficient

growth boundary, $D_{c}^{*}(x(t))$. Furthermore, the interpretation of the comparative statics result regarding $x(t)$ comes from the fact that I consider a one-sided barrier control problem (Harrison, 1985).

\section{Q.E.D.}




\section{Appendix D: Proof of the Certainty Case}

In the absence of any uncertainty $x(\tau)=x+\alpha \tau$. Substituting this equation into Equation (8) yields the objective function of the developer as given by

$$
V(x)=\max _{T} U(T, x)=\left[\frac{1}{\rho}\left(x\left(\alpha T+\frac{\alpha}{\rho}-\theta D-\gamma-n g(k)\right)\right)-F\right] e^{-\rho T} .
$$

Intuitively, a landowner needs to decide either to develop one unit parcel of land immediately at the initial date or to delay development. The former occurs if $\alpha \leq 0$, while the latter occurs if $\alpha>0$. Suppose that the landowner develops that parcel of land at a date $T=T^{*}>0$. Differentiating Equation (D1) with respect to $T$ and then setting the result equal to zero yields

$$
\frac{\partial U\left(T^{*}, x\right)}{\partial T}=\left[\rho F+n g(k)-(x-\theta D-\gamma)-\alpha T^{*}\right] e^{-\rho T^{*}}=0 .
$$

The second-order condition is given by

$$
\frac{\partial^{2} U\left(T^{*}, x\right)}{\partial T^{2}}=-\alpha e^{-\rho T^{*}}<0,
$$

which holds for $\alpha>0$. Equation (D2) indicates that the interior solution for $T$ is given by

$$
T^{*}=\frac{1}{\alpha}[\gamma+\rho F+n g(k)+\theta D-x]>0,
$$

which requires that

$$
\gamma+\rho(F+n g(k))+\theta D>x .
$$

Imposing $T^{*}=0$ and replacing $x$ by $x^{*}$ yields $x^{*}$ as shown in Equation (33). Substituting $T=T^{*}$ into Equation (D1) yields the option value of postponing 
development as given by

$$
V(x)=\frac{\alpha}{\rho^{2}} e^{-\rho T^{*}} .
$$

Q.E.D. 


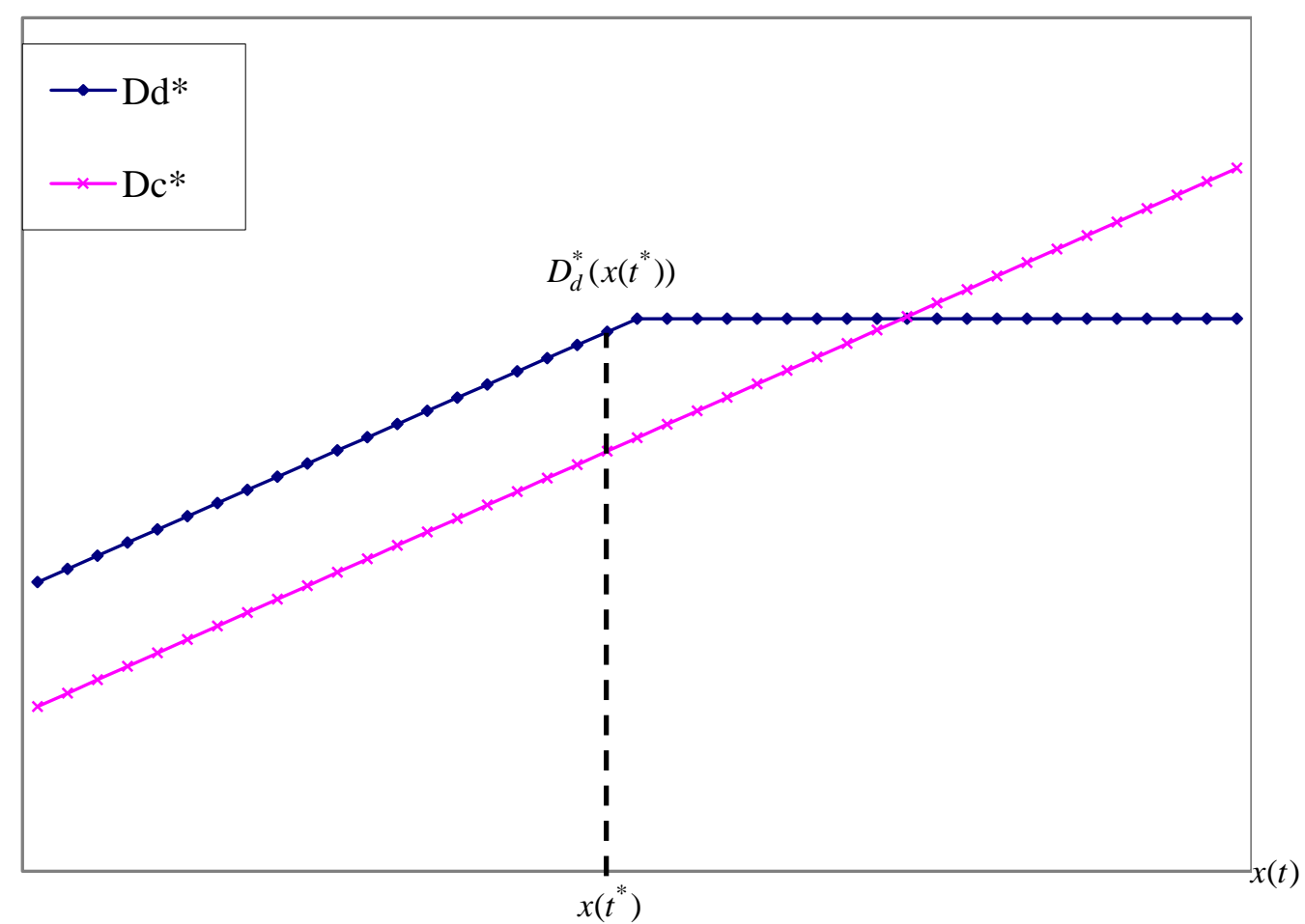

Fig. 1. The efficient city boundary control in the absence of any uncertainty. This graph shows that the efficient city boundary proposed by Ding et al. (1999) imposes no control before $t=t^{*}$ such that the efficient city boundary is the same as the equilibrium city boundary, $D_{d}^{*}(x(t))$. Immediately after $t=t^{*}$, the regulator should impose a fixed level city boundary at $D_{d}^{*}\left(x\left(t^{*}\right)\right)$ once and for all. In contrast, the efficient city boundary in my framework, $D_{c}^{*}(x(t))$, is always smaller than the equilibrium level, $D_{d}^{*}(x(t))$. 


\section{References}

Anas, A. and Pines, D. 2008. Anti-sprawl policies in a system of congested cities. Regional Science and Urban Economics, 38, 408-423.

Anas, A. and Rhee, H.-J. 2006. Curbing excess sprawl with congestion tolls and urban boundaries. Regional Science and Urban Economics 36, 510-541.

Anas, A. and Rhee, H.-J. 2007. When are urban growth boundaries not second-best policies to congestion tolls. Journal of Urban Economics, 61, 263-286.

Arnott, R. 1979. Unpriced transport congestion. Journal of Economic Theory, 21, 294-316.

Bertola, G. and R. J., Caballero. 1994. Irreversibility and aggregate investment. Review of Economic Studies, 61, 223-246.

Brueckner, J. K. 1990. Growth controls and land values in an open city. Land Economics, 66(3), 237-248.

Brueckner, J. K. 1995. Strategic control of growth in a system of cities, Journal of Public Economics, 57, 393-416.

Brueckner, J. K. 1997. Infrastructure financing and urban development: the economics of impact fees. Journal of Public Economics, 66, 383-407.

Brueckner, J. K. 2007a. Urban growth boundaries: An effective second-best remedy for unpriced traffic congestion? Journal of Housing Economics, 16, 263-273. 
Brueckner, J. K. 2007b. Government land-use interventions: an economic analysis, paper presented at the $4^{\text {th }}$ Urban Research Symposium, World Bank, Washington, D.C.

Brueckner, J. K. 2011. Lectures on Urban Economics, The MIT Press, Cambridge, Massachusetts.

Brueckner, J. K. and Lai, F.-C. 1996. Urban growth with resident landowners. Regional Science and Urban Economics, 26, 125-143.

Capozza, D. and Helsley, R. 1990. The stochastic city. Journal of Urban Economics, $28,187-203$.

Capozza, D. and Li, Y. 1994. The intensity and timing of investment: the case of land. American Economic Review, 84(4), 889-904.

Capozza, D. and Sick, G. 1994. The risk structure of land markets. Journal of Urban Economics, 35, 297-319.

Cho, M. 1997. Congestion effects of optimal growth restrictions: A model and empirical analysis. Real Estate Economics, 25, 409-438.

Cooley, T. F. and LaCivita, C. J. 1982. A theory of growth controls. Journal of Urban Economics, 12, 129-45.

Cox, W. and Pavletich, H. 2012. $8^{\text {th }}$ Demographic International Housing Affordability Survey: 2012 Ratings for Metropolitan Markets, Performance Urban Planning, Christchurch, New Zealand.

Ding, C., Knaap, G. J. and Hopkins, L. D. 1999. Managing urban growth with urban 
growth boundaries: A theoretical analysis. Journal of Urban Economics, 46, $53-68$.

Dixit, A. K. and Pindyck, R. S. 1994. Investment under Uncertainty. Princeton, NJ: Princeton University Press.

Engle, R., Navarro, P. C. and Carson, R. 1992. On the theory of growth controls. Journal of Urban Economics, 32, 269-283.

Fujita, M. 1982. Spatial patterns of residential development. Journal of Urban Economics, 12(1), 22-52.

Gennaio, M.-P., Hersperger, A.M. and Bürgi, M. 2009. Containing urban sprawl-Evaluating effectiveness of urban growth boundaries set by the Swiss Land Use Plan. Land Use Policy, 26, 224-232.

Harrison, J. M. 1985. Brownian Motion and Stochastic Flow Systems. New York: John Wiley and Sons.

Helsley, R. W. and Strange, W. C. 1995. Strategic growth controls, Regional Science and Urban Economics, 25, 435-460.

Jaeger, W. K. and Plantinga, A. J. 2007. How have land-use regulations affected property values in Oregon? Special Report 1077. Oregon State University Extension Service.

Jou, J.-B. 2004. Environment, irreversibility and optimal effluent standards. The 
Australian Journal of Agricultural and Resource Economics, 48(1), 127-158.

Jou, J.-B. 2012. Efficient boundary controls in the presence of population externalities, and stochastic rents. Quarterly Review of Economics and Finance, 52, 349-357.

Jou, J.-B. and Lee, T. 2008. Taxation on land value and development when there are negative externalities from development. Journal of Real Estate Finance and Economics, 36(1), 103-120.

Juergensmeyer, J. C. and Roberts, T. E. 2003. Land Use Planning and Development Regulation Law, West Group, St. Paul, Minnesota

Kanemoto, Y. 1977. Cost-benefit analysis and the second-best land use for transportation. Journal of Economic Theory, 4, 483-503.

Kono, T., K. K. Joshi, T. Kato and T. Yokoi. 2012. Optimal regulation on building size and city boundary: An effective second-best remedy for traffic congestion externality. Regional Science and Urban Economics, 42(4), 619-630.

Lee, T. and Jou, J.-B. 2010. Urban spatial development: a real options approach. Journal of Real Estate Finance and Economics, 40, 161-187.

Mayo, S. and Sheppard, S. 2001. Housing supply and the effects of stochastic development control. Journal of Housing Economics, 10, 109-128.

Pindyck, R. S. 1988. Irreversible investment, capacity choice, and the value of the firm. American Economic Review. 78(5), 969-985. 
Pines, D. and E. Sadka. 1985. Zoning, first-best, second-best and third-best criteria for allocating land to roads. Journal of Urban Economics, 17:167-183.

Sakashita, N. 1995. An economic theory of urban growth control. Regional Science and Urban Economics, 25, 427-434.

Sasaki, K. 1998. Optimal urban growth controls. Regional Science and Urban Economics, 28, 475-496.

Turnbull, G. K. 1988. Residential development in an open city. Regional Science and Urban Economics, 18(2), 307-320.

Turnbull, G. K. 2004. Urban growth controls: transitional dynamics of development fees and growth boundaries. Journal of Urban Economics, 55(2), 215-237.

Wheaton, W. G. 1998. Land use and density in cities with congestion. Journal of Urban Economics, 43, 258-272. 